Meta

Journal des tradlucteurs

Translators' Journal

\title{
Querelles de traducteurs... de français : querelles d'Allemand?
}

\section{Philippe Desjardins}

Volume 14, numéro 1, mars 1969

URI : https://id.erudit.org/iderudit/002555ar

DOI : https://doi.org/10.7202/002555ar

Aller au sommaire du numéro

Éditeur(s)

Les Presses de l'Université de Montréal

ISSN

0026-0452 (imprimé)

1492-1421 (numérique)

Découvrir la revue

Citer cet article

Desjardins, P. (1969). Querelles de traducteurs... de français : querelles d'Allemand? Meta, 14(1), 40-42. https://doi.org/10.7202/002555ar d'utilisation que vous pouvez consulter en ligne.

https://apropos.erudit.org/fr/usagers/politique-dutilisation/ 
QUERELLES DE TRADUCTEURS... DE FRANCAIS: QUERELLES D'ALLEMAND?

Dans l'exorde de la communication qu'il donnait au séminaire sur les langues de la diplomatie canadienne, tenu à Ottawa le 26 août dernier, M. René de Chantal, doyen de la Faculté des lettres de l'Université de Montréal, rappelait avec humour le débat presque acrimonieux dont il avait été témoin un jour où, encore 
étudiant, il faisait ses premières armes en traduction dans un ministère: à un traducteur qui avait employé l'expression "retard apporté à répondre (à une lettre) », le réviseur soutenait mordicus qu'en l'occurrence l'expression était à proscrire, car elle impliquait - chose inconcevable — un acte de propos délibéré de la part des agents du ministère.

Si l'histoire ne dit pas qui l'emporta, du traducteur ou du réviseur, l'anecdote fournit une entrée en matière appropriée à ce petit article, auquel on pourrait assigner deux objets: d'abord montrer que les querelles de français * ne sont pas d'hier et que leur fin n'est pas pour demain; ensuite, puisqu'elles sont presque invariablement des querelles d'Allemand, exhorter - même si l'on sait la partie perdue d'avance - la gent traductrice et paratraductrice à s'employer à des activités plus fructueuses. Et j'y arrive tout de suite.

Il s'agit précisément de la sempiternelle querelle sur les expressions tout de suite et de suite. M. Maurice Rat ${ }^{1}$, qu'il n'est pas besoin - sans doute - de présenter aux abonnés de Meta, nous en livre ainsi l'origine:

On connaît aussi l'anecdote où l'on voit Conrart, qui fut le premier "perpétuel » de l'Académie, disputer avec Boisrobert, Chapelain et Patru sur l'usage, et particulièrement sur la distinction qu'il sied de faire entre de suite et tout de suite. Le colloque se prolongeant, les quatre disputeurs décidèrent d'aller vider leur querelle à la célèbre auberge $A u x$ Vendanges de Bourgogne devant un plat d'huîtres et du vin blanc.

\&Veuillez nous ouvrir de suite quatre douzaines d'huîtres, dit Boisrobert à l'écaillère.

- Oui, ajouta Conrart, servez-les-nous tout de suite ... »

La commère regarda ses clients:

«Mais, fit-elle, s'il faut que j'ouvre vos huîtres de suite, il m'est impossible de vous les servir tout de suite! 》

Savez-vous à quand remonte cette querelle? Ni plus ni moins qu'au tout début $\mathrm{du} \mathrm{XVII}^{\mathrm{e}}$ siècle, ces personnages, tous admis à l'Académie, étant nés en $1603,1592,1595$ et 1604 respectivement.

Or, trois siècles et demi plus tard, la sage leçon de français de la marchande d'huîtres n'a pas encore porté ses fruits et la querelle dure toujours (de décennie en décennie): $M$. Joseph Hanse ${ }^{2}$ doit rappeler la distinction entre de suite et tout de suite en 1949, M. Adolphe Thomas ${ }^{3}$ en 1956, M. Jacques Capelovici ${ }^{4}$ en 1966 et le Petit Robert ${ }^{5}$ en 1967, sans compter les innombrables chroniqueurs

* Ce n'est pas aux lecteurs de META qu'il faut rappeler la subtilité avec laquelle le français distingue la nationalité et la langue d'une personne. M. Jacques Capelovici, collaborateur de Vie et langage, l'exemplifiait lors de la $2^{\mathrm{e}}$ Biennale de la Fédération du français universel, à Québec, en septembre 1967, par une anecdote éloquente que je reproduis de mémoire: Une jeune Française se rend au pays des querelles oiseuses pour y apprendre la langue indigène. Histoire d'agrémenter ses études (ou était-ce parce que, poète, elle cherchait une belle rime?), elle s'y fait un amant, avec toute la discrétion qu'impose l'initiative. Une amie, plus animée de sollicitude que forte en français, lui écrit quelques semaines plus tard et, comble d'ignorance des règles élémentaires de grammaire, fait ainsi une entorse des plus monumentales aux règles de bienséance: "Comment va ton Allemand ? " lui demande-t-elle. Se croyant trahie, à cause de cette intempestive majuscule, notre linguiste se met à table et, comme aurait dit La Fontaine, pour une majuscule, Martine perdit son amant.

1. Cf. Défense de la langue française (Paris), 45 (juin 1968): 10.

2. Dictionnaire des difficultés grammaticales et lexicologiques, Bruxelles, Baude, 1949.

3. Dictionnaire des difficultés de la langue française, Paris, Larousse, 1956.

4. Parlons (correctement) français, Paris, Télé 7 jours, 1966.

5. Paris, Société du Nouveau Littré, 1967. 
de langage qui n'ont cessé et qui ne cessent encore, presque sur la fin du $\mathrm{Xx}^{\mathrm{e}}$ siècle, de la signaler à tout bout de champ. Et $\mathrm{M}$. Rat ${ }^{6}$ de reprendre le souhait de Bossuet: "que si la langue de la multitude ne saurait être contrainte, elle souffre du moins d'être dirigée $\gg$.

Mais, dirigée par qui ? On aura beau invoquer qu'il y a une faute de français dans les statuts mêmes de l'Académie, que la grammaire de cette dernière viole dans un exemple donné à la page $\mathrm{X}$ une règle qu'elle édicte à la page $\mathrm{Z}$, que cet institut avance toujours à l'âge nucléaire au rythme du siècle de sa fondation, n'empêche que, sauf intervention de l'État, l'Académie reste, jusqu'à nouvel ordre, le seul organisme habilité à légiférer en la matière. Mais, voilà ! ses verdicts n'ont pas force coercitive et, malgré ses décisions, la pagaille continue de régner.

Dernièrement, les Quarante donnaient le feu vert au mot contexte, avec l'acception d'《ensemble de circonstances», acception d'ailleurs consignée dans le Petit Robert. On eût espéré, après cette consécration officielle, que la question fût réglée, classée, et qu'on changerait de disque. Illusion! M. Paul Camus ${ }^{7}$, méritoire secrétaire général de Défense de la langue française, qui mène le bon combat depuis de nombreuses années, avec une persévérance et un courage dignes des plus respectueux éloges, vient néanmoins d'opposer à l'Académie, à propos de contexte, un non serviam non équivoque: "L'Académie, «greffier de l'usage », s'est inclinée devant l'usage actuel. Si notre action parvient à faire triompher la raison - pourquoi pas? - on ne parlera plus de contexte quand il ne s'agira pas d'un texte, et l'Académie, «greffier de l'usage », sanctionnera très volontiers cette évolu'ion heureusement régressive. »

Faut-il s'étonner ensuite qu'après avoir signalé que «l'évolution du vocabulaire pose aux locuteurs français des problèmes chaque jour plus nombreux et plus difficiles à résoudre », M. Pierre Pamart ${ }^{8}$, général à la retraite doublé d'un linguiste averti, regrette que «d'autres groupements qui ont entrepris, à titre plus ou moins officiel » de chercher des solutions à ces problèmes, voient souvent leurs interventions, donc leur efficacité, malheureusement contestées: "Encore heureux lorsqu'ils ne sont pas séparés par des divergences doctrinales qui contribuent à mettre en doute la validité de leur action auprès des hommes de bonne volonté non spécialistes qui recherchent la vérité, parfois en vain ...»

À la manière de Mac-Mahon qui, l'inspiration freinée devant l'immensité des inondations de Toulouse, avait dû se résigner à balbutier: "Que d'eau! Que d'eau!», il ne nous reste plus, face à l'étendue et à la multiplicité des querelles de français, qu’à nous exclamer: «Que de mots! Que de mots! »

PhIl IPPE DesJardins

6. Défense de la langue française, 45 (juin 1968).

7. Ibid., 45: 5 .

8. Vie et langage, 187 (juillet 1967): 362 et 366. 